\title{
EDITORIAL
}

La teoría económica ortodoxa, como presupuesto para el funcionamiento de la misma, consagra el axioma del "hombre económico», entendido como el convencimiento de que el hombre actúa «maximizando beneficios y minimizando costos» en la toma de decisiones económicas. Es decir, actúa racionalmente al actuar en el mercado ${ }^{1}$. El acotado axioma, junto con el equilibrio del mercado y las preferencias estables, constituye la base del pensamiento económico moderno, en sus más diversas concepciones.

\section{El Derecho Público Económico}

Resulta necesario establecer un régimen jurídico que establezca los lineamientos del funcionamiento del régimen económico, puesto que el mercado, en determinadas circunstancias, puede mostrar distorsiones que no se corrigen únicamente con la racionalidad de los operadores de aquel, por ello es necesaria la intervención del Estado para hacerlo efectivo. En ese sentido, la función del Estado debe limitarse a realizar el papel de un árbitro de las actividades económicas, antes que a ser un interventor o un actor en el mercado, respetando así el principio de subsidiaridad.

A su vez, el poder público económico que es ejercido por el Estado y la Administración Pú-

1 TORRES, Juan. Análisis económico del Derecho. Madrid: Editorial Tecnos S. A., 1987, pp. 30-31. blica en materia económica — pudiendo en ocasiones ser ejercido por particulares - debe ser sometido a los controles propios del Estado de Derecho, en especial los provenientes de la Constitución política, la cual por definición controla y organiza el poder político ${ }^{2}$, que indiscutiblemente incluye también aquel que interviene en la economía. Caso contrario, dicho ejercicio puede ser arbitrario, perjudicando los derechos de los particulares y a la sociedad en su conjunto.

De eso trata el Derecho Público Económico, de determinar los parámetros de la intervención del Estado en la economía, obviamente dentro del contexto de una economía de mercado - o una economía social de mercado, que técnicamente es lo mismo-y sin vulnerar los derechos fundamentales, generando resultados eficientes en el mercado.

Es así que el sistema económico requiere que existan reglas claras para la intervención del Estado en la economía. Ello demanda, además, que dichas reglas hayan sido emitidas previamente, que sean conocidas por todos $y$ que no sean modificadas sin que exista una real justificación técnica y jurídica, lo cual, evidentemente, incluye la estabilidad de la norma constitucional ${ }^{3}$.

2 LOEWENSTEIN, K. Teoría de la Constitución. Madrid: Ariel, 1982, p. 149 y ss.

3 GUZMAN, C. La constitución politica: Un análisis funcional. Lima: Gaceta Jurídica, 2015, p. 30 y ss. 
Lo antes señalado implica que la tendencia del Derecho Público Económico es hacia la libertad del ciudadano y no hacia la restricción de sus derechos fundamentales, y que deben tomarse en cuenta las leyes básicas de la economía, en particular, las leyes de la oferta y la demanda, así como las leyes que rigen el equilibrio en el mercado. Caso contrario, la intervención administrativa en el mercado termina generando mayores distorsiones en vez de corregirlas. Tenemos, por ejemplo, la regulación económica, que tiene por finalidad que las decisiones privadas no perjudiquen el interés general ${ }^{4}$; sin embargo, las dificultades que entraña la regulación económica son bastante altas, dada la posibilidad de politización de la misma, así como el riesgo de empleo de la regulación por parte de actores económicos, quienes buscan verse favorecidos por la misma. Por ello, la regulación económica debe estar debidamente limitada y circunscrita a supuestos específicos, en especial, considerando que la misma implica limitaciones a derechos fundamentales.

\section{Las herramientas empleadas en el Derecho Público Económico}

Para el estudio del Derecho Público Económico, es necesario emplear las herramientas

4 CASES Lluis. Derecho administrativo de la defensa de la competencia. Madrid: Marcial Pons, 1995, p. 25. adecuadas. Es obvio que el análisis jurídico tradicional no es suficiente para comprender el funcionamiento y aplicación — cuestión que muchos especialistas en este tema no lo tienen aún del todo claro- , por ello se requiere recurrir a otras disciplinas.

La primera de dichas disciplinas - como no puede ser de otra manera- es la propia economía. Es evidente, por ejemplo, que el Derecho Constitucional no puede ser entendido sin emplear instrumentos provenientes de la Ciencia Política, así como no puede analizarse debidamente el Derecho Administrativo sin el apoyo de la Gestión Pública. De la misma manera, es imposible entender el Derecho Público Económico sin el apoyo de la Ciencia Económica.

Ahora bien, el análisis económico tradicional, así como el análisis económico del derecho son medulares para ello, sin contar otras disciplinas de especial importancia para el estudio que vamos a efectuar en esta Revista, como son la Ciencia Política, la Gestión Pública —en sus nuevas vertientes, que incluyen los conceptos de reforma y modernización del Estado-, e incluso, la Filosofía Política y la Sociología.

En cuanto a la Gestión Pública, es preciso señalar que el Derecho Público Económico debe tener un enfoque de gestión, necesario para una mayor eficiencia en la intervención administrativa, incorporando conceptos de la modernización del Estado, como son la eficiencia, la 
estructura del Estado, la gestión por procesos, la gestión por objetivos, la simplificación administrativa, entre otras. Este enfoque es clave para que los actores estatales empleen las herramientas de gestión de la manera más apropiada.

Finalmente, todo ello ocurre sin descuidar importantes instrumentos propiamente jurídicos, como la doctrina más reputada en la materia, así como el precedente administrativo y la jurisprudencia, en especial la que es emitida por el Tribunal Constitucional (TC). Sin embargo, en este último punto debemos adelantar que el análisis debe ser crítico, puesto que el TC no siempre ha establecido juicios adecuados respecto de los conceptos y principios que se van a describir en los diversos artículos que componen la Revista.

\section{Finalidad de la Revista de Derecho Público Económico}

En este orden de ideas, la Revista de Derecho Público Económico tiene como objetivo ser un medio de publicación académico de la Escuela de Posgrado de la Universidad Continental y, en particular, de la Maestría en Derecho Administrativo Económico, incluye por ello diversos temas que abarcan desde el Derecho Constitucional Económico hasta las Contrataciones del Estado, pasando por las diversas formas de regulación económica que existen.

Asimismo, la Revista publica artículos acadé- micos en las áreas propias del Derecho Administrativo Económico, fomentando la investigación, así como la generación y difusión del conocimiento en esta materia, que mucha falta hace hoy en día. Es justo notar que existe un gran desconocimiento de estos temas, lo cual se manifiesta con claridad en el reciente proceso electoral, donde los candidatos emplearon los conceptos propios de esta materia de manera incorrecta.

En ese sentido, la Revista de Derecho Público Económico tiene por finalidad cubrir el vacío existente en publicaciones de esta naturaleza, tanto en el Perú como en el extranjero. De hecho, no existe una publicación que sea igual en el Perú. Además, en la actualidad existen pocas publicaciones de este tipo en Latinoamérica y en el resto del mundo, no obstante la importancia medular que esta materia tiene en este contexto.

\section{Contenido de la primera edición de la Revista}

En este primer número, se hallarán diversos artículos sobre determinados temas que componen dicha materia. Así Juan José Martínez Ortiz escribe sobre el «Marco teórico para entender (y enfrentar) los problemas de desempeño, integridad y corrupción en el sector público». Asimismo, tenemos el trabajo de Pierino Stucchi, «Fundamentos para otorgar autonomía constitucional al Indecopi». 
A estos artículos se agrega el de Eduardo Melgar, «Análisis de las implicaciones de la asignación de talento humano en las agencias públicas de enforcement»; así como el trabajo de Nadia Palomino «Análisis constitucional de la eliminación del Régimen de Contratación Administrativa de Servicios en la Administración Pública»; al que se añade el artículo de Humberto Valenzuela «Alcances sobre el Derecho a la movilidad sostenible en el Perú»; y el trabajo de Alfonso Garcés, «Invierte.pe y los desafíos que enfrenta para mejorar la ejecución de la inversión pública: ¿Un error de diagnóstico?». Además, tenemos el artículo de Pedro Gamio, «Energías renovables alternativas, un reto para el Perú», el trabajo de Hugo Gómez, «Las medidas de salvaguardia en la Comunidad Andina»; el artículo de Victoria Pérez, «Los impedimentos para contratar con el estado y los principios de libre concurrencia y competencia», y finalmente el trabajo de quien escribe estas líneas, «El principio de subsidiaridad empresarial del Estado».

Christian Guzmán Napurí

DiRECTOR GeNeral DE LA REVISTA 